\title{
Frost resistance of concretes containing ground granulated blast-furnace slag
}

\author{
Pawet Łukowski ${ }^{1, *}$, Ali Salih $^{2}$, and Joanna J. Sokołowska ${ }^{1}$ \\ ${ }^{1}$ Warsaw University of Technology, Faculty of Civil Engineering, al. Armii Ludowej 16, Warsaw 00- \\ 637, Poland \\ ${ }^{2}$ Roadstone Ltd., A CRH Group Company, Fortunestown, Tallaght, Dublin 24, Ireland
}

\begin{abstract}
The paper deals with the influence of addition of ground granulated blast-furnace slag (GGBS) on the frost resistance of concrete. GGBS is a valuable modifier of concrete, having the latent hydraulic properties and particularly improving the chemical resistance of concrete. However, the performance of concretes with blast-furnace slag under freezing and thawing action is still not explained fully and remains a subject to discussion. The authors have investigated the concretes containing various amounts of GGBS and the portland cement CEM I, with various values of water to binder ratio, with and without the use of air-entraining admixture. The results of research show that the addition of blast-furnace slag causes some worsening of the frost resistance of concrete. The extent of this worsening depends on the water to binder ratio and the aeration of the concrete. However, even under the least favourable conditions, the concretes with GGBS addition have met the requirements of frost resistance after 200 cycles of freezing and thawing, given in the Standard PN-B-06265.
\end{abstract}

\section{Introduction}

Ground granulated blast-furnace slag (GGBS) is one of the concrete additions. According to PN-EN 206:2016 [1], GGBS is type II addition, together with fly ash and silica fume. It belongs to the group of latent hydraulic materials; PN-EN 206 recommends $k$ value of 0.6 for GGBS used with cements CEM I and CEM II/A. The blast-furnace slag is also an important constituent of many common cements according to PN-EN 197-1 [2].

Ground granulated blast-furnace slag is formed by rapid cooling of the liquid slag, which is produced during smelting of the iron ore in the blast furnace. After grinding, it forms fine powder; the grinding process, increasing the specific area of the material, is of favour for its hydraulic activity. The slag is, therefore, the waste material from the production of the iron. According to Neville [3], there is about $300 \mathrm{~kg}$ of the slag produced together with $1000 \mathrm{~kg}$ of the pig iron.

The main components of the blast-furnace slag are calcium oxide $\mathrm{CaO}(30-50 \%)$, silicon dioxide $\mathrm{SiO}_{2}$ (28-40\%), aluminum oxide $\mathrm{Al}_{2} \mathrm{O}_{3}$ (6-24\%) and magnesium oxide $\mathrm{MgO}$ (1$18 \%$ ). The slag shows hydraulic ability after activation by such substances like lime (also

\footnotetext{
*Corresponding author: P.Lukowski@il.pw.edu.pl
} 
this produced during Portland cement hydration), sodium hydroxide, sodium carbonate, water glass, gypsum, and others.

The use of the ground granulated blast-furnace slag as the concrete addition meets the requirements of the strategy of sustainable development in construction and is justified from the economical point of view. As reported by Deja [4], the mineral additions can have a positive influence on the durability of the binders; this effect can also be attributed to GGBS [5-8]. However, the technical properties of cement concretes containing ground granulated blast-furnace slag are not fully recognized yet and their durability under frost action still creates the particular uncertainty.

The aim of the presented research was to recognize the effect of ground granulated blastfurnace slag addition on the durability of concrete under freezing and thawing action. The blast-furnace slag was used as a partial replacement for cement (the maximum degree of substitution was $70 \%$ of the cement mass). The variable factors were water to binder ratio in the concrete mix and use (or not) of the air-entraining admixtures.

\section{Materials and methods}

\subsection{Materials used and mix proportions}

Portland cement CEM I 42,5R was used for manufacturing the concretes for testing. The chemical composition of the cement as well as the slag, determined according to PN-EN 1962 [9], are presented in the Table 1.

Table 1. Chemical composition of the cement and slag used in research.

\begin{tabular}{|l|c|c|}
\hline \multirow{2}{*}{ Component } & \multicolumn{2}{|c|}{ Content, mass \% } \\
\cline { 2 - 3 } & CEM I 42.5R & GGBS \\
\hline $\mathrm{CaO}$ & 63.30 & 42.16 \\
\hline $\mathrm{SiO}_{2}$ & 19.39 & 35.89 \\
\hline $\mathrm{Al}_{2} \mathrm{O}_{3}$ & 5.05 & 10.86 \\
\hline $\mathrm{Fe}_{2} \mathrm{O}_{3}$ & 3.38 & 0.61 \\
\hline $\mathrm{MgO}^{*}$ & 1.51 & 7.13 \\
\hline $\mathrm{TiO}_{2}$ & 0.20 & 0.76 \\
\hline $\mathrm{Alkalis}\left(\mathrm{Na}_{2} \mathrm{O}_{\text {eq }}\right)$ & 0.66 & 0.62 \\
\hline Sulfates $\left(\mathrm{SO}_{3}\right)$ & 3.42 & 0.11 \\
\hline Chlorides & 0.04 & 0.02 \\
\hline Sulfides & - & 0.50 \\
\hline Loss on ignition & 2.53 & 1.16 \\
\hline Unsoluble residue & 0.54 & 0.18 \\
\hline
\end{tabular}

Density of the ground granulated blast-furnace slag (determined by the use of LeChatelier method according to PN-B-06714-02 [10]) was $2860 \mathrm{~kg} / \mathrm{m}^{3}$, which belongs to the range of the values typical for this material. The SEM observations showed that the morphology of the GGBS grains is also typical with domination of irregular shapes (Fig. 1). 

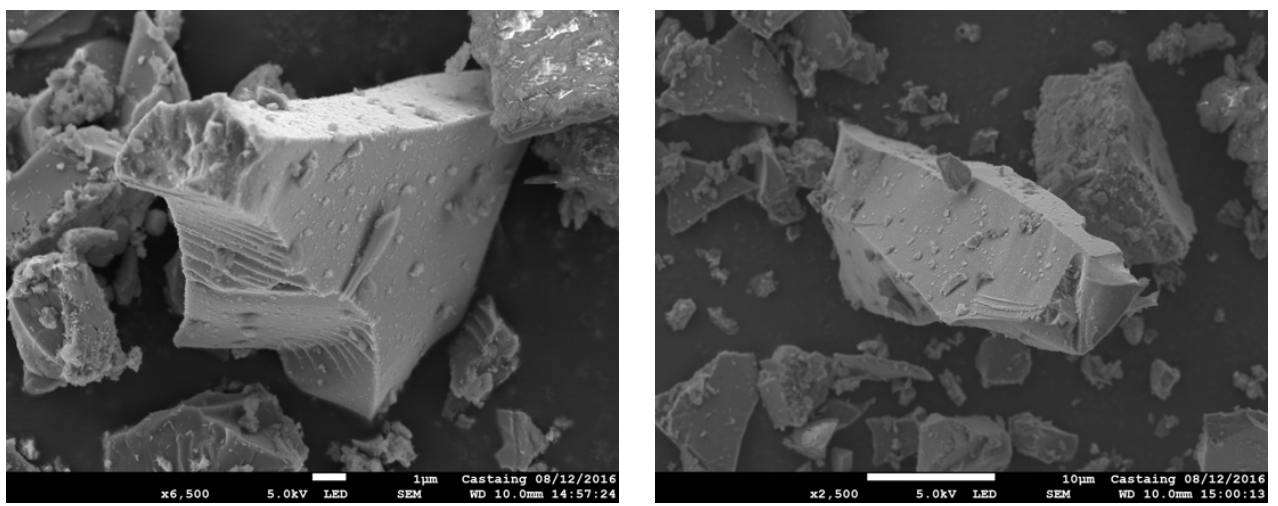

Fig. 1. SEM images of GGBS grains.

The aggregate conforming to PN-EN 12620 [11] was used to make the tested concretes. The aggregate consists of natural sand and crushed hornfels aggregates with the fractions 2/4 $\mathrm{mm}, 4 / 8 \mathrm{~mm}$ and $8 / 16 \mathrm{~mm}$. Tap water was used as the mixing water. The commercially available superplasticizer (HRWRA) and air-entraining agent were used as the admixtures for concrete.

The concrete mixes with various water to binder ratio (where binder means cement or the sum of cement and GGBS), i.e. $0.45,0.40$ and 0.37 , are presented in the Table 2. The conistence S3 acc. to PN-EN 206 was assumed, i.e. the slump 100-150 mm acc. to PN-EN 12350-2 [12]. The content of a polycarboxylate superplasticizer was adjusted to obtain this consistence class. The content of the air-entraining agent (when used) was constant and equal to $0.25 \%$ of the cement mass.

Table 2. Mix compositions of the tested concretes

\begin{tabular}{|c|c|c|c|c|c|c|c|c|c|c|c|c|}
\hline \multirow{3}{*}{ Components } & \multicolumn{12}{|c|}{ Water to binder ratio } \\
\hline & \multicolumn{4}{|c|}{0.45} & \multicolumn{4}{|c|}{0.40} & \multicolumn{4}{|c|}{0.37} \\
\hline & \multicolumn{12}{|c|}{ Contents per $\mathrm{w} 1 \mathrm{~m}^{3}$ of the concrete mix, $\mathrm{kg}$} \\
\hline $\begin{array}{l}\text { \% of GGBS in } \\
\text { binder mass }\end{array}$ & 0 & 30 & 50 & 70 & 0 & 30 & 50 & 70 & 0 & 30 & 50 & 70 \\
\hline GGBS & 0 & 102 & 170 & 238 & 0 & 108 & 180 & 252 & 0 & 111 & 185 & 259 \\
\hline Cement & 340 & 238 & 170 & 102 & 360 & 252 & 180 & 108 & 370 & 259 & 185 & 111 \\
\hline Water & \multicolumn{4}{|c|}{153} & \multicolumn{4}{|c|}{144} & \multicolumn{4}{|c|}{137} \\
\hline Sand $0 / 2 \mathrm{~mm}$ & \multicolumn{4}{|c|}{519} & \multicolumn{4}{|c|}{521} & \multicolumn{4}{|c|}{523} \\
\hline Gravel 2/4 mm & \multicolumn{4}{|c|}{389} & \multicolumn{4}{|c|}{390} & \multicolumn{4}{|c|}{392} \\
\hline Gravel $4 / 8 \mathrm{~mm}$ & \multicolumn{4}{|c|}{372} & \multicolumn{4}{|c|}{273} & \multicolumn{4}{|c|}{274} \\
\hline Gravel 8/16 mm & \multicolumn{4}{|c|}{758} & \multicolumn{4}{|c|}{761} & \multicolumn{4}{|c|}{765} \\
\hline HRWRA & \multicolumn{4}{|c|}{1.40} & \multicolumn{4}{|c|}{1.48} & \multicolumn{4}{|c|}{1.52} \\
\hline
\end{tabular}




\subsection{Methods of testing}

The air content in the concrete mixes was measured acc. to PN-EN 12350-7 [13].

The frost resistance of concretes was determined following PN-B-06265 [14] (the national supplement to EN 206). The method uses $100 \mathrm{~mm}$ cubic specimens; 6 of them is periodically freezed in air $(4 \mathrm{~h})$ and thawed in water $(4 \mathrm{~h})$, while the other 6 is stored for comparison. After 200 freezing and thawing cycles the changes of mass and compressive strength of the specimens were determined. Also, the visual inspection of the specimens was done. The tests were performed after 28 days of curing.

\section{Results and discussion}

An air-entraining agent was used in the constant amount $0.25 \%$ of the cement mass. This way the air content in the mixes was obtained as required by PN-EN 206 for the concretes exposed to frost (exposition classes XF2-XF4), i.e. $\geq 4 \%$. Only slight influence of the slag on the level of air-entraining was observed (Fig. 2).
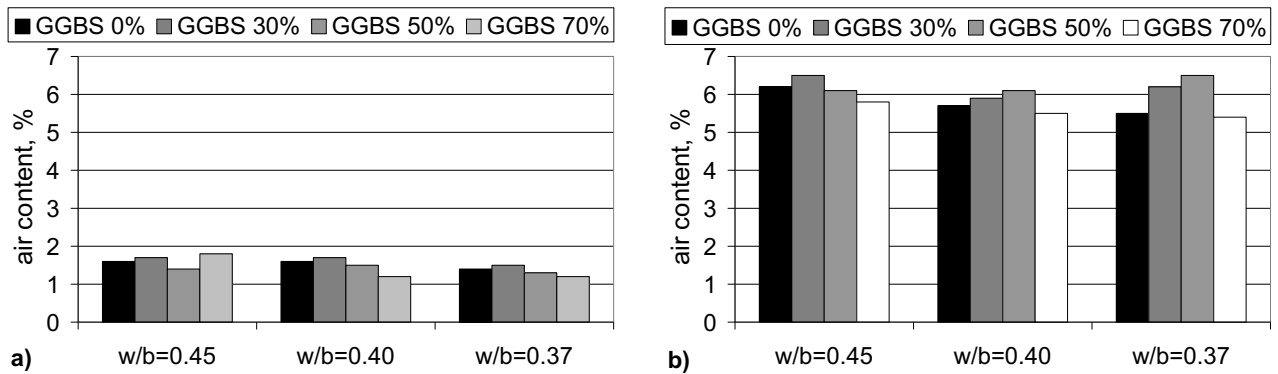

Fig. 2. Air content in the concrete mixes with various amounts of GGBS: a) without air-entraining agent, b) with air-entraining agent.

Figures 3-5 present the absolute loss of the compressive strength of the tested concretes after 200 cycles of freezing and thawing. The percentage loss of strength, which is the basis for evaluation of the frost resistance of concrete acc. to PN-B-06265, is presented in the Figures 6 and 7, while the loss of mass is presented in the Figure 8.

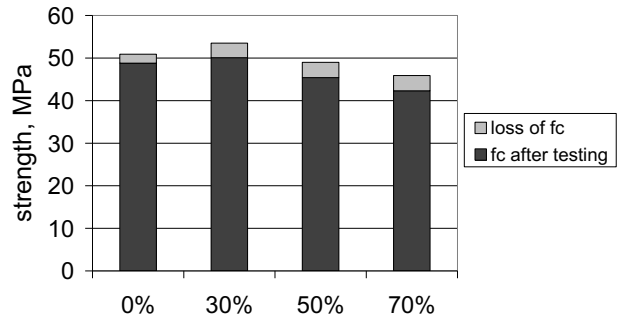

a)

GGBS content in the binder, mass \%

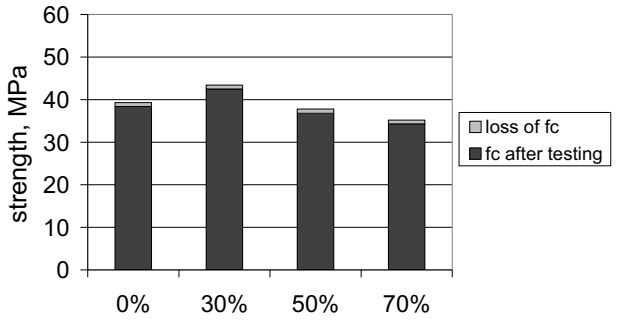

b) GGBS content in the binder, mass \%

Fig. 3. Absolute loss of compressive strength of concretes with various amounts of GGBS; water to binder ratio 0.45 , after 200 cycles of freezing and thawing: a) without air-entraining agent, b) with air-entraining agent. 


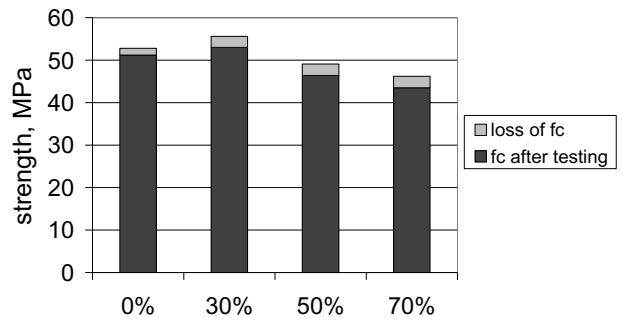

a) GGBS content in the binder, mass $\%$

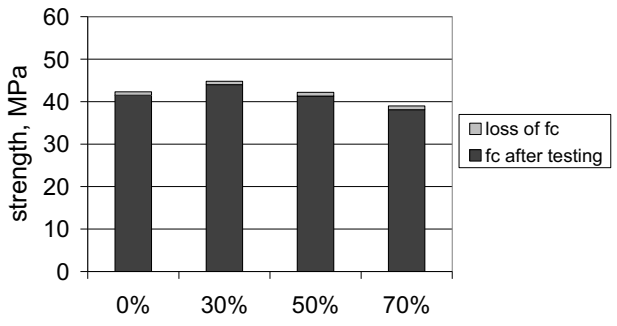

b) GGBS content in the binder, mass $\%$

Fig. 4. Absolute loss of compressive strength of concretes with various amounts of GGBS; water to binder ratio 0.40 , after 200 cycles of freezing and thawing: a) without air-entraining agent, b) with air-entraining agent.

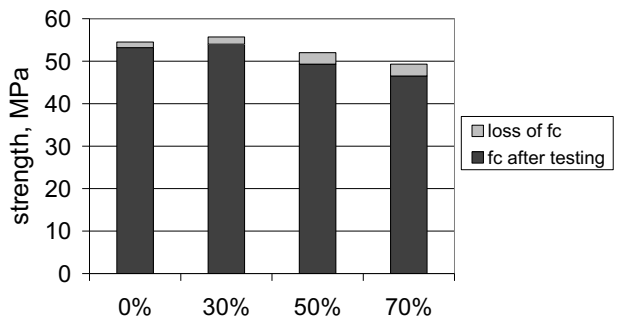

a) GGBS content in the binder, mass $\%$

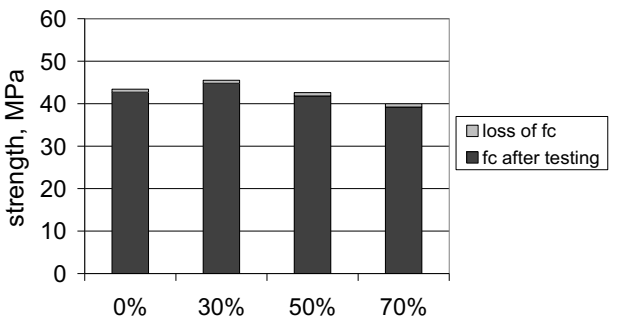

b) GGBS content in the binder, mass \%

Fig. 5. Absolute loss of compressive strength of concretes with various amounts of GGBS; water to binder ratio 0.37 , after 200 cycles of freezing and thawing: a) without air-entraining agent, b) with air-entraining agent.

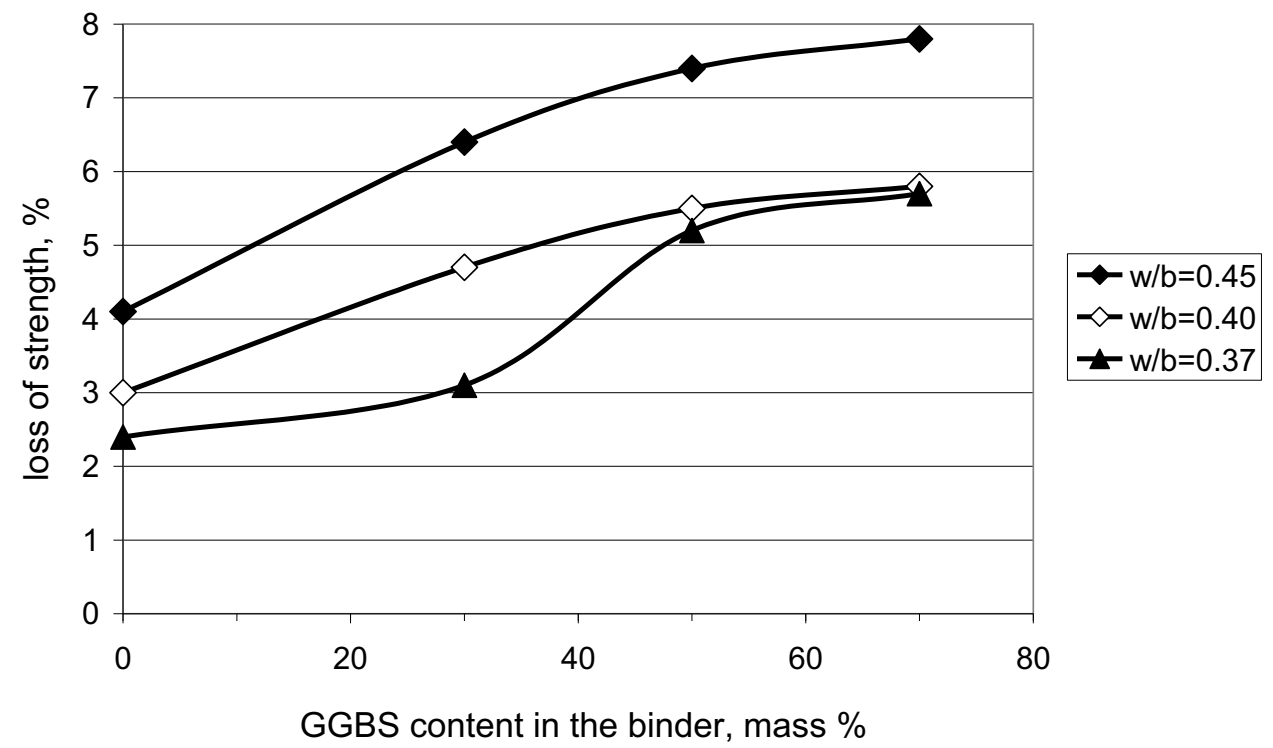

Fig. 6. Relative loss of compressive strength of concretes with various amounts of GGBS and water to binder ratio after 200 cycles of freezing and thawing: the concretes without air-entraining agent. 


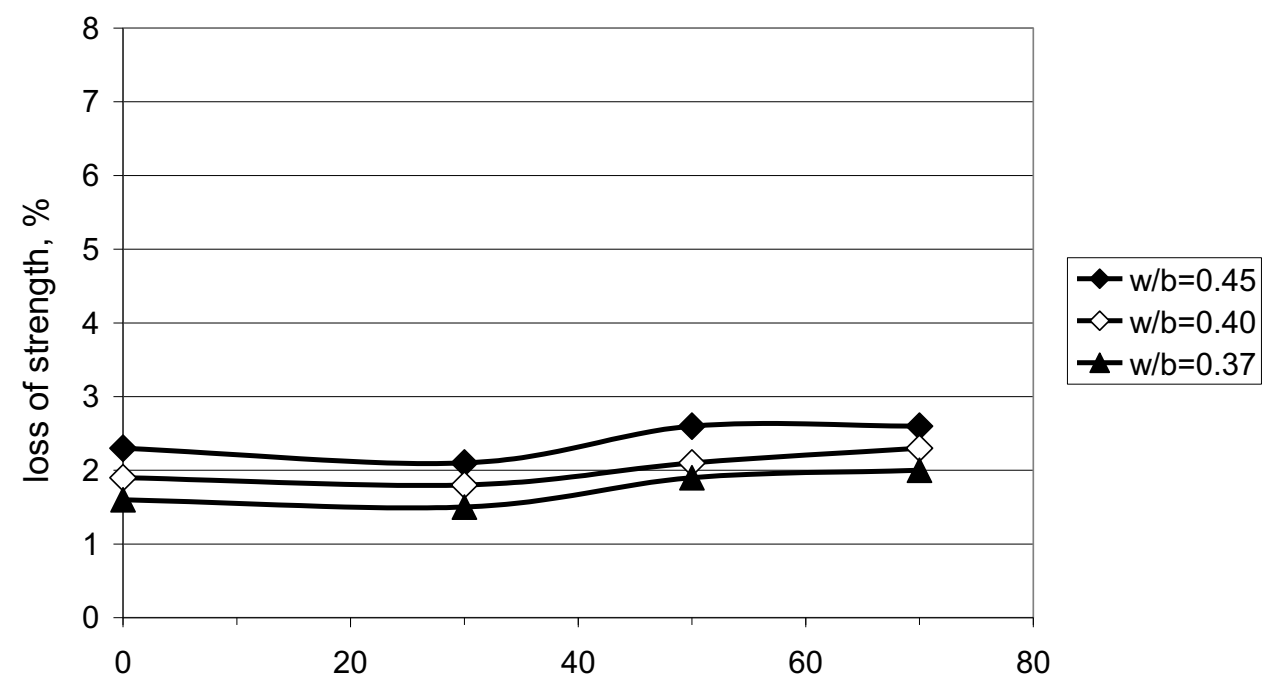

GGBS content in the binder, mass \%

Fig. 7. Relative loss of compressive strength of concretes with various amounts of GGBS and water to binder ratio after 200 cycles of freezing and thawing: the concretes with air-entraining agent.
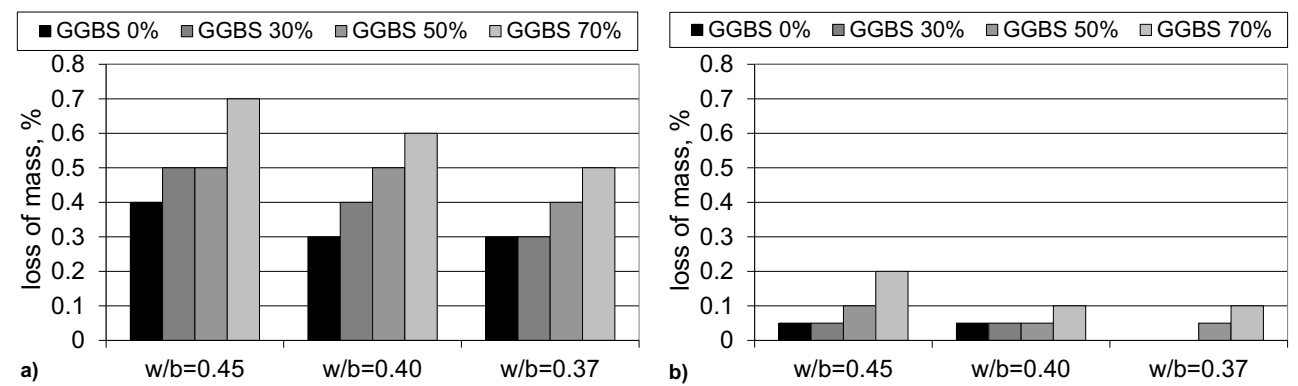

Fig. 8. Loss of mass of concretes with various amounts of GGBS and water to binder ratio; CEM I; after 200 cycles of freezing and thawing: a) without air-entraining agent, b) with air-entraining agent.

The last element of the evaluation of concrete resistance to frost action is visual inspection of the specimens during and after the given number of freezing and thawing cycles. The status of the example set of specimens is documented in the Figure 9.

Three criteria of evaluation of concrete frost resistance have been formulated in PN-B06265 :

- $\quad$ strength decrease of specimens after freezing and thawing considering the reference (not freezed) specimens should not exceed $20 \%$,

- $\quad$ loss of mass of specimens after freezing and thawing should not exceed $5 \%$,

- $\quad$ there is no cracking visible on the specimens after freezing and thawing. 


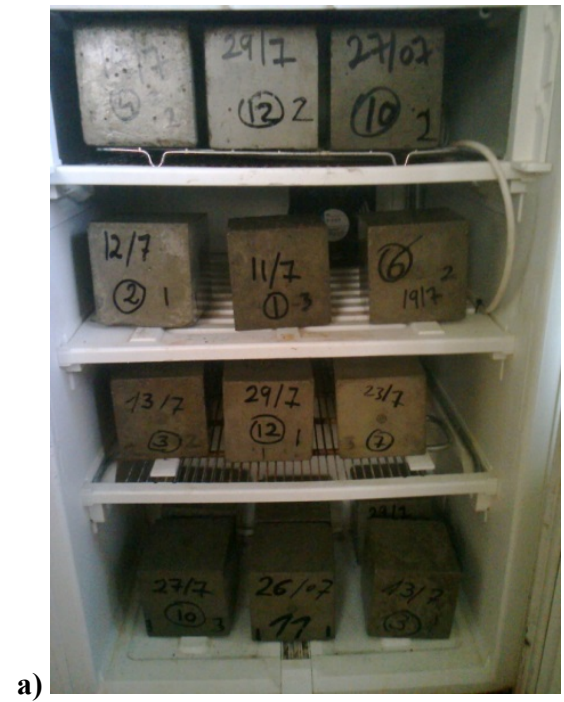

b)

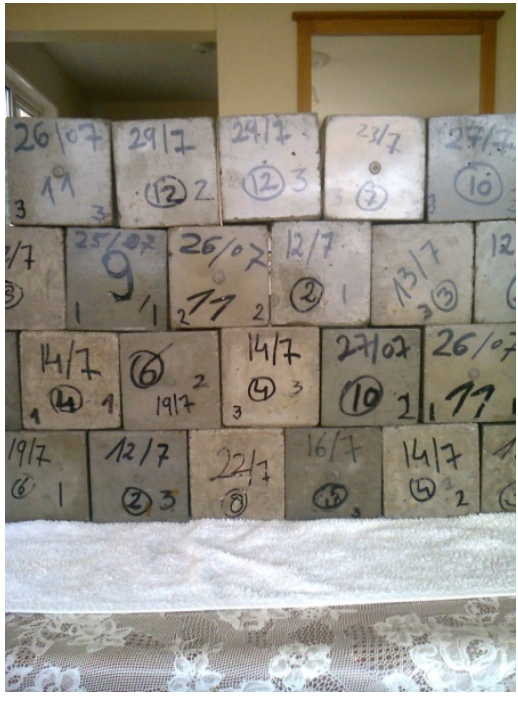

Fig. 9. Tested concrete specimens: a) in the freezing chamber, b) after 200 cycles of freezing and thawing

Following these requirements we have observed that:

- the use (or not) of an air-entraining agent, the water to binder ratio and the addition of ground granulated blast-furnace slag all influence the degree of compressive strength loss of the concrete after 200 cycles of freezing and thawing. This decrease is, as expected, deeper in the case of the concretes without air-entraining agent and with higher value of water to binder ratio.

The effect of GGBS on the strength loss of concrete after freezing and thawing depends on aeration of concrete (or the lack of it). When no air-entraining agent is used, the loss of strength grows with increasing content of slag. However, the compressive strength of such concretes after 200 cycles of freezing and thawing did not lower by more than $8 \%$, even at $70 \%$ GGBS content in the binder.

The influence of GGBS is different in the case of the aerated concrete. The maximum loss of strength after 200 cycles of freezing and thawing did not exceed $3 \%$ then; the degree of strength lowering only slightly depends on the slag content. Some minimum has been even observed for $30 \%$ GGBS content in the binder.

Therefore, the determined losses of compressive strength are in any case far from the value allowed by PN-B-06265, i.e. $20 \%$.

- The higher content of ground granulated blast-furnace slag caused bigger losses of mass of concretes after freezing and thawing. However, the losses were very slight in every case and did not exceed $0.7 \%$ for the non-aerated concretes and $0.2 \%$ for aerated concretes. The mass losses of the concretes containing GGBS after 200 cycles of freezing and thawing did not approach to the value allowed by PN-B-06265, i.e. 5\%.

- The visual inspection of the specimens, both during and after the cycles of freezing and thawing, has revealed no cracks nor other damages of concrete.

Taking into consideration the aforementioned observations, we conclude that the addition of ground granulated blast-furnace slag causes some worsening of the frost resistance of concrete, if no air-entraining agent is used. However, the criteria of frost resistance formulated in PN-B-06265 are still met even for large 70\% content of GGBS in the binder. The proper aeration protects the concrete containing blast-furnace slag against the consequences of the cyclic freezing and thawing in the same degree as the concrete without addition of GGBS. 


\section{Sum up and conclusions}

The subject of this paper was the evaluation of the influence of ground granulated blastfurnace slag (GGBS) on the frost resistance of concrete. The use of blast-furnace slag as a mineral addition of type II for concrete, with replacement of part of the cement with GGBS, is favourable from the ecological point of view, allowing to rational utilization of the industrial waste or by-products. Moreover, it makes possible to decrease the consumption of Portland cement, production of which causes significant emission of carbon dioxide. All this is in accordance with the strategy of sustainable development in construction. The concretes containing the cheaper than cement GGBS are also economically attractive.

The particular subject of the study was to discuss possibility of using concrete containing ground granulated blast-furnace slag in the moderate climate. In such conditions, the material in the structure is usually exposed to cyclic freezing and thawing action. The results of the investigation allowed to learn that the addition of the blast-furnace slag causes some worsening of the frost resistance of concrete; the degree of this worsening depends on the water to binder ratio and the aeration of concrete. However, even under the least favourable conditions, the concretes with GGBS addition have met the requirements of the frost resistance after 200 cycles of freezing and thawing, given in PN-B-06265.

Taking the above into consideration, we conclude that the properly designed, manufactured and cured concretes, containing even large amount of the ground granulated blast-furnace slag, can be used in the conditions of threat of the frost aggression.

The authors would like to thank Faculty of Civil Engineering of Warsaw University of Technology for the support of this research.

\section{References}

1. PN-EN 206 (2016)

2. PN-EN 197-1 (2012)

3. A.M. Neville, Properties of Concrete (5th ed. Pearson, 2012)

4. J. Deja, 10th International Congress on Chemistry of Cement 4, 4iv015 (1997)

5. J. Deja, Ceramika - Ceramics 83 (2004)

6. J. Małolepszy, J. Deja, 4th CANMET/ACI International Conference on Durability of Concrete 1, 189 (1997)

7. J. Deja, Cement Concrete Comp. 25, 357 (2003)

8. P. Łukowski, A. Salih, Procedia Engineering 108, 47 (2015)

9. PN-EN 196-2 (2013)

10. PN-B-06714-02 (1976)

11. PN-EN $12620+\mathrm{A} 1(2010)$

12. PN-EN 12350-2 (2011)

13. PN-EN 12350-7 (2011)

14. PN-B-06265 (2017) (draft) 